The Agriculturists 15(2): 88-100(2017) ISSN 2304-7321 (Online), ISSN 1729-5211 (Print)

\title{
The influence of Waterlogging Period on Yield and Yield Components of Mungbean (Vigna radiata L. Wilczek)
}

\author{
M. R. Amin ${ }^{1}$, M. A. Karim², Q. A. Khaliq ${ }^{2}$, M. R. Islam² and S. Aktar ${ }^{3}$ \\ ${ }^{1}$ On-Farm Research Division, Bangladesh Agricultural Research Institute, Gazipur-1701, Bangladesh; \\ ${ }^{2}$ Department of Agronomy, Bangabandhu Sheikh Mujibur Rahman Agricultural University, Gazipur- \\ 1706, Bangladesh; ${ }^{3}$ Pulse Research Sub-station, Bangladesh Agricultural Research Institute, Gazipur- \\ 1701, Bangladesh \\ *Corresponding author and Email: aminagr70@gmail.com
}

Received: 14 September 2017

Accepted: 22 December 2017

\begin{abstract}
Yield performance of 10 selected mungbean (Vigna radiata L. Wilczek) genotypes, viz. GK-7, GK-48, GK-65, VC-6173A, CO-3, IPSA-12, IPSA-13, IPSA-15, BARI Mug-5 and BUmug 2 was evaluated under waterlogged condition in the research field of Bangabandhu Sheikh Mujibur Rahman Agricultural University, Gazipur, Bangladesh during April to July 2011. Waterlogging depth was 3-5 $\mathrm{cm}$, created by irrigation from tap water and imposed at 22 days after emergence of seedlings which was maintained for 2, 4 and 6 days in the three different treatments. Yield and yield contributing characters of the mungbean genotypes were significantly affected by waterlogging. The longer the waterlogging period, the more was the reduction in seed yield and yield contributing characters. Among the 10 genotypes, IPSA-13 performed the best in respect of grain yield production under waterlogging condition, which was followed by VC-6173A and BUmung 2.
\end{abstract}

Keywords: Mungbean genotypes, Waterlogging period, Yield and yield attributes.

\section{Introduction}

Waterlogging is a major constraint for production of many crops (Leul and Zhou, 1999). In tropical and subtropical regions, severe crop losses are caused by prolonged seasonal rainfall. Waterlogging greatly impairs plant performance, although many of the plant species have the ability to develop a combination of mechanisms enabling them to grow under flooding (Kozlowski, 1984). Oxygen deficiency is the main constraint for plants during waterlogging (Crawford and Brandle 1996; Vartapetain and Jackson, 1997). Duration and level of soil submersion and the growth stage of plants during waterlogging are the major factors affecting plant performance under waterlogging. It is generally considered that the longer the waterlogging period, the higher is the adverse effects on plant. The severity of waterlogging on plant damage is influenced by the rate of water input, water flow out from the rooting zone and by the water absorbing capacity of the soil. However, for longer-term survival of the plant under oxygen deficient condition, oxygen must be introduced into the interior of roots in amounts that support respiration and activities such as mineral and water uptake (Jackson, 1983). Greenway et al. (1994) reported that the survival mechanism might vary depending on the crops, growth habits and duration of waterlogging. 
Mungbean (Vigna radiata L. Wilczek) is cultivated widely in the tropical and sub-tropical regions and considered to be a susceptible crop to soil waterlogging (Hamid et al. 1991; Miah et al; 1991; Rosario and Faustino, 1986). Large decreases in yield after only one day of waterlogging have been reported in many legumes (Cannell et al., 1979; Jackson, 1979) including soybean (Wien et al., 1979). Waterlogging is reported to reduce growth and chlorophyll content and responsible for death of roots and reduced yield of mungbean (Islam et al., 2007; Islam et al., 2008). The findings of Yadav and Saxena (1998) and Ahmed et al. (2002) revealed that the mungbean plants had the ability to recover quickly from waterlogging damages, and produce grain yield without significant reduction. Varietal difference of mungbean to waterlogging effect was reported by Bagga et al. (1984) and the effect on growth and physiological process, duration of flooding and stage at which the plant encountered the stress was studied by Islam (2003). However, there is lack of information on the effect of waterlogging duration on yield performance of mungbean genotypes. Under field condition the waterlogging duration varies with intensity and duration of rain, and soil types as well. Therefore, this experiment was carried out to analyze the effect of waterlogging duration on yield and yield components of some selected mungbean genotypes.

\section{Materials and Methods}

The experiment was conducted at the Agronomy Research field of Bangabandhu Sheikh Mujibur Rahman Agricultural University, Gazipur-1706, Bangladesh from April to July, 2011. The soil of the experimental plots was silty clay of shallow Red Brown Terrace soil belongs to Salna series under Madhupur Tract (AEZ 28).

Ten mungbean genotypes viz. GK-48, GK-65, VC-6173A, CO-3, IPSA-12, IPSA-13, IPSA-15, BARI Mung-5, BUmug 2 and GK-7 were considered for the study. The split plot design was followed in distributing treatments with three replications. Four waterlogging treatments were:

(i) $\mathrm{T}_{1}=$ Control (non-waterlogged),

(ii) $\mathrm{T}_{2}=2$-day waterlogging,

(iii) $\mathrm{T}_{3}=4$-day waterlogging, and

(iv) $\mathrm{T}_{4}=6$-day waterlogging.

The size of each main plot was $(10 \mathrm{~m} \times 1 \mathrm{~m})=10$ $\mathrm{m}^{2}$ and each sub-plot was $(1 \mathrm{~m} \times 1 \mathrm{~m})=1 \mathrm{~m}^{2}$. Drain in between two main plots was $1 \mathrm{~m}$ and polythene sheet was used as barrier so that flooded water cannot soak the neighbouring experimental plots. At the border of each plot, one additional row of mungbean was grown to avoid border effect. When the seedlings were 22 days old, waterlogging with $3-5 \mathrm{~cm}$ of standing water was maintained continuously above the soil surface for 2 days (48 hours), 4 days (96 hours) and 6 days (144 hours) and thereafter standing water was removed. Normal irrigation was given to the control plots for establishment of the crop.

The experimental land was ploughed properly and at the time of first ploughing cowdung at 10 $\mathrm{t} \mathrm{ha}^{-1}$ was applied. A blanket dose of fertilizers @ 40-25-30 kg ha- ${ }^{-1}$ of N-P-K was applied and incorporated into the soil at the time of final land preparation. Seeds of uniform size and shape were sorted from their stock and treated with Vitavex $200 @ 2$ g per kg seed. The seeds were soaked in water for 4 hours before sowing and imbibed seeds were selected for sowing. Seeds were sown with a spacing of $30 \mathrm{~cm} \times 10 \mathrm{~cm}$. Seedlings were thinned out after one week of emergence keeping one healthy seedling of uniform growth in each plot. During growing period, average minimum and maximum temperature ranged between $28.16^{\circ}$ and $32.46^{\circ} \mathrm{C}$, respectively. The total rainfall during the experimentation period was $1008.10 \mathrm{~mm}$. Admire@ $2 \mathrm{ml} \mathrm{L}^{-1}$ was sprayed to protect the plants from insects. Other management practices were done adequately to maintain normal growth of seedlings.

The crops were harvested at maturity and yield parameters were recorded. Ten plants of each 
genotype were harvested from control and waterlogged plots for data collection. Pods of each plot of each genotype were harvested separately and the yield parameters were recorded. The number of mature pods of each plant was recorded and mean was expressed on per plant basis. The number of total seeds in each plant was recorded and mean was expressed on per plant basis. For every treatment, sample seeds were taken and 1000-seed were counted by Multi Auto Counter (Model DC 1 No. 102, Everwell Corporation, Tokyo, Japan) and weighed with an electronic balance. Seed yield of each plot was recorded and adjusted to $12 \%$ moisture content and mean was expressed on per plant basis.

Weather data were collected from the meteorological station of Bangabandhu Sheikh Mujibur Rahman Agricultural University, Salna, Gazipur.

The data on different parameters were subjected to statistical analysis. Microsoft EXCEL and MSTAT-C software programs were used wherever appropriate to perform statistical analysis. All recorded data were analyzed using analysis of variance (ANOVA) and means were compared using Least Significant Difference (LSD) test according to Gomez and Gomez (1984).

\section{Results and Discussion}

The effect of different duration of waterlogging and mungbean genotypes interacted significantly on plant height at harvest (Table 1). Plant height of 2 days waterlogged plants reduced significantly over control treatment at different extent depending on the genotypic characteristics. Plant height varied significantly between the controls and waterlogged plants in GK-48, GK-65, CO-3, IPSA-12 and BUmung 2, although non-waterlogged control plants were apparently taller than waterlogged plants, though the variation was not significant in other genotypes. Plant height of IPSA-13 was unaffected by 2 days waterlogging. The rate of reduction over control treatment was greater in IPSA-12 (35.02\%) and the least in GK-7 $(3.60 \%)$.

Significant reduction in plant height was observed when the mungbean genotypes were exposed to 4 days waterlogging. Plant height of all genotypes significantly reduced under 4 days waterlogged plants. The rate of reduction over the control treatment was the highest in GK-65 $(53.54 \%)$ and the lowest in GK-7 (20.85\%). Plant height of BARI mung-5 was unaffected at harvest.

The significant variation in plant height might be due to varietal characters and adverse effect of continuous 6 days waterlogging on mungbean genotypes. From the Table 1, it was apparent that the detrimental effect of longer period of waterlogging for 6 days shortened the plant height about half of the non-waterlogged control. The highest reduction was recorded in GK-65 (57.48\%) followed by CO-3 $(55.41 \%)$. The least reduction in plant height was found in BARI Mung-5 (31.63\%) followed by IPSA-12 $(29.45 \%)$ and VC-6173A (30.46\%).

Genotypic difference in the production of leaf number plant ${ }^{-1}$ due to waterlogging duration was significant at harvest (Table 2). The number of leaves at harvest reduced due the senescence and abscission of lower leaves. Number of leaves plant $^{-1}$ reduced in 2 days waterlogged plants over control treatment significantly. CO-3 produced the highest number of leaves plant ${ }^{-1}(24.00)$ and the rate of reduction was $52.79 \%$. The lowest rate of reduction over control treatment was recorded in VC-6173A (3.68\%). The number of leaf plant ${ }^{-1}$ was statistically similar between the control and 4 days waterlogged plants in GK-48, GK-65, VC-6173A, IPSA-13 and BARI mung-5. The highest percentage of reduction was in $\mathrm{CO}-3$ $(42.38 \%)$ although the number of leaves in waterlogged plants was significantly higher than that of non-waterlogged control of other mungbean genotypes. 
Table 1. Interaction effect waterlogging period on plant height $\left(\mathrm{cm} \mathrm{plant}^{-1}\right)$ of mungbean genotypes at harvest.

\begin{tabular}{lcccc}
\hline \multirow{2}{*}{ Genotypes } & \multicolumn{4}{c}{ Period of waterlogging } \\
\cline { 2 - 5 } & Control & 2 days & 4 days & 6 days \\
\hline GK-7 & 52.40 & 50.51 & 41.47 & 30.33 \\
GK-48 & 60.28 & 49.33 & 41.57 & 29.20 \\
GK-65 & 66.56 & 49.23 & 30.92 & 28.30 \\
VC-6173A & 57.67 & 52.03 & 35.85 & 40.10 \\
CO-3 & 91.57 & 67.98 & 59.07 & 40.83 \\
IPSA-12 & 57.62 & 37.44 & 44.22 & 40.65 \\
IPSA-13 & 49.90 & 44.64 & 31.16 & 27.10 \\
IPSA-15 & 50.09 & 47.77 & 32.81 & 26.88 \\
BARI Mung-5 & 45.48 & 36.83 & 37.16 & 31.07 \\
BUmung 2 & 53.21 & 40.37 & 29.06 & 26.90 \\
\hline LSD & \multicolumn{5}{c}{.05 } & \multicolumn{5}{c}{10.52} \\
\hline CV\% & \multicolumn{5}{c}{} \\
\hline
\end{tabular}

Table 2. Interaction effect of waterlogging period on leaf number plant $^{-1}$ of mungbean genotype at harvest.

\begin{tabular}{|c|c|c|c|c|}
\hline \multirow[t]{2}{*}{ Genotypes } & \multicolumn{4}{|c|}{ Period of waterlogging } \\
\hline & Control & 2 days & 4 days & 6 days \\
\hline GK-7 & 6.66 & 4.20 & 5.13 & 3.06 \\
\hline GK-48 & 5.66 & 4.06 & 4.46 & 2.33 \\
\hline GK-65 & 5.60 & 3.86 & 3.46 & 2.66 \\
\hline VC-6173A & 7.33 & 7.06 & 6.56 & 5.06 \\
\hline $\mathrm{CO}-3$ & 24.00 & 11.33 & 13.83 & 8.33 \\
\hline IPSA-12 & 11.00 & 9.00 & 8.56 & 7.66 \\
\hline IPSA-13 & 4.46 & 3.53 & 3.46 & 3.06 \\
\hline IPSA-15 & 11.31 & 2.93 & 2.86 & 2.80 \\
\hline BARI Mung-5 & 4.33 & 3.86 & 2.93 & 2.73 \\
\hline BUmung 2 & 5.40 & 3.80 & 2.93 & 1.93 \\
\hline $\mathrm{LSD}_{0.05}$ & \multicolumn{4}{|c|}{2.535} \\
\hline $\mathrm{CV} \%$ & \multicolumn{4}{|c|}{16.46} \\
\hline
\end{tabular}

Number of leaves plant ${ }^{-1}$ reduced significantly than control treatment due to the 6 days waterlogging except in GK-7, GK-65, and IPSA13. The percentage of reduction in GK-65, VC6173A, IPSA-12, IPSA-13 and BARI mung-5 were around $30 \%$ and it was more than $50 \%$ in GK-48, CO-3, IPSA-15 and BUmung 2. From the table, it was observed that the percentage of reduction of leaves plant $^{-1}$ in some genotypes viz. CO-3, IPSA-12, VC-6173A was noticeably higher at maturity. This might be due to the recovery ability of those genotypes overcoming waterlogging stress at later stage of growth. Similarly, Kumar et al. (2013) observed quick recovery of leaf growth in tolerant genotypes.

Mungbean genotypes and waterlogging duration interacted significantly on branch plant ${ }^{-1}$ at harvest (Table 3 ). The branching habit of a plant is genetically determined and it was reduced significantly when plants were waterlogged for variable periods. The highest number of branch 
plant $^{-1}$ under control treatment was in CO-3 (5.33) followed by GK-48 (2.00), VC-6173A (1.86) and IPSA-12 (1.73) and the least was in BUmung 2 and BARI Mung-5 (1.13). All the genotypes under 2 days waterlogged condition had a single number of branch plant ${ }^{-1}$ except $\mathrm{CO}$ 3 (3.13), IPSA-12 (1.66) and VC-6173A (1.13). Similar trend was also observed in 4 days waterlogged plants and most of the genotypes produced a single branch except CO-3 (2.00) and IPSA-12 (1.00). Lateral shoot development could be seen in healthy plants whereas the lateral shoot growth retarded in waterlogged plants. Minchin et al. (1978) demonstrated that the yield reduction by waterlogging at the vegetative stage of cowpea was closely related to the reduction of lateral shoot development. Under 6 day's waterlogged condition, some genotypes such as GK-65, VC-6173A, IPSA-13, IPSA-15, BARI Mung-5 and BUmung 2 produced mostly one branch plant ${ }^{-1}$. Even some genotypes viz. GK-7 and GK-48 did not produce any branch at all.

Table 3. Interaction effect of waterlogging period on branch plant ${ }^{-1}$ of mungbean genotypes at harvest.

\begin{tabular}{lcccc}
\hline Genotypes & \multicolumn{4}{c}{ Period of waterlogging } \\
\cline { 2 - 5 } & Control & 2 days & 4 days & 6 days \\
\hline GK-7 & 1.00 & 0.40 & 0.80 & 0.00 \\
GK-48 & 2.00 & 0.53 & 0.20 & 0.00 \\
GK-65 & 1.00 & 0.53 & 0.26 & 0.33 \\
VC-6173A & 1.86 & 1.13 & 0.93 & 0.66 \\
CO-3 & 5.33 & 3.13 & 2.00 & 1.00 \\
IPSA-12 & 1.73 & 1.66 & 1.00 & 1.06 \\
IPSA-13 & 1.00 & 0.20 & 0.20 & 0.20 \\
IPSA-15 & 2.33 & 0.60 & 0.20 & 0.20 \\
BARI Mung-5 & 1.13 & 0.46 & 0.20 & 0.26 \\
BUmung 2 & 1.13 & 0.53 & 0.20 & 0.26 \\
\hline LSD & & & 1.113 & \\
CV\% & & 89.64 & \\
\hline
\end{tabular}

Table 4. Interaction effect of waterlogging period on pod plant ${ }^{-1}$ of mungbean genotypes.

\begin{tabular}{lcccc}
\hline Genotypes & \multicolumn{4}{c}{ Period of waterlogging } \\
\cline { 2 - 5 } & Control & 2 days & 4 days & 6 days \\
\hline GK-7 & 12.10 & 10.80 & 6.53 & 3.67 \\
GK-48 & 8.73 & 7.40 & 5.93 & 6.60 \\
GK-65 & 10.20 & 9.93 & 4.80 & 3.53 \\
VC-6173A & 10.53 & 10.13 & 7.33 & 5.40 \\
CO-3 & 11.67 & 10.00 & 9.00 & 4.00 \\
IPSA-12 & 9.13 & 8.00 & 6.40 & 4.07 \\
IPSA-13 & 13.10 & 10.33 & 8.13 & 5.33 \\
IPSA-15 & 9.73 & 9.60 & 6.17 & 3.47 \\
BARI Mung-5 & 8.26 & 8.00 & 7.13 & 4.87 \\
BUmung 2 & 9.73 & 8.06 & 7.00 & 5.60 \\
\hline LSD 0.05 & \multicolumn{4}{c}{1.60} \\
CV\% & \multicolumn{4}{c}{12.74} \\
\hline
\end{tabular}


The reduction of branch plant ${ }^{-1}$ might be caused by the competition of assimilates between roots and the other organs in waterlogging affected plants reported by Nawata (1989).

The number of pod plant ${ }^{-1}$ was not affected significantly by waterlogging for 2 days but interacted significantly among the genotypes when plants waterlogged for 4 and 6 days (Table 4). A positive correlation between pod plant $^{-1}$ and seed yield plant ${ }^{-1}$ of mungbean genotypes existed when plants were waterlogged for 4 days $(\mathrm{r}=0.78)$ and 6 days $(\mathrm{r}=0.80)$.

Waterlogging for 4 days significantly affected the number of pod plant ${ }^{-1}$ in all the genotypes except BARI mung-5 (Table 4). Islam et al. (2014) reported that the number of pods plant ${ }^{-1}$ in mungbean affected significantly due to waterlogging stress. The highest number of pods plant $^{-1}$ produced by the genotypes IPSA-13 (13.10) was identical with GK-7 (12.10) followed by CO-3 (11.67) in non-waterlogged control treatment. Other genotypes produced more than 8.00 pods plant $^{-1}$. The highest percentage of reduction over control treatment in pod plant ${ }^{-1}$ was recorded in GK-65 $(52.94 \%)$ followed by GK-7 (46.03\%) and the lowest was in BARI mung-5 (13.68\%). Umaharan et al. (1997) reported that waterlogging during the vegetative period resulted in a significant decline in pod yield of cowpea and the reductions reflected in the number of pod plant ${ }^{-1}$. The functional relationship between pod plant $^{-1}$ and seed yield $\left(\mathrm{g} \mathrm{plant}^{-1}\right)$ showed almost linear and becomes exponential when plant had more than 8.00 pods plant $^{-1}$ (Fig. 1).

The number of pod plant ${ }^{-1}$ was greatly reduced in 6 days waterlogged plants than those of nonwaterlogged control treatment and longer the period of waterlogging the fewer was the number of pods plant ${ }^{-1}$ (Table 4). Nawata et al. (1991) reported that in yard long bean, the yield reduction in plants subjected to long-term waterlogging was due to reduction in pod number plant ${ }^{-1}$. The percentage of reduction over control treatment in pod formation due to continuous 6 days waterlogging ranged from $24.39 \%$ to $69.66 \%$ depending on the genotypes. Pod formation in most genotypes reduced by $50 \%$ over control treatment except GK-48 (24.39\%), BARI Mung-5 (41.04\%), BUmung 2 $(42.44 \%)$, and VC-6173A (48.71\%). Islam (1994) reported that waterlogging significantly reduced pods plant ${ }^{-1}$ in mungbean and $36 \%$ more pods were produced in control plants than waterlogged plants. The functional relationship between pod plant ${ }^{-1}$ and seed yield showed linear relationship (Fig. 2).

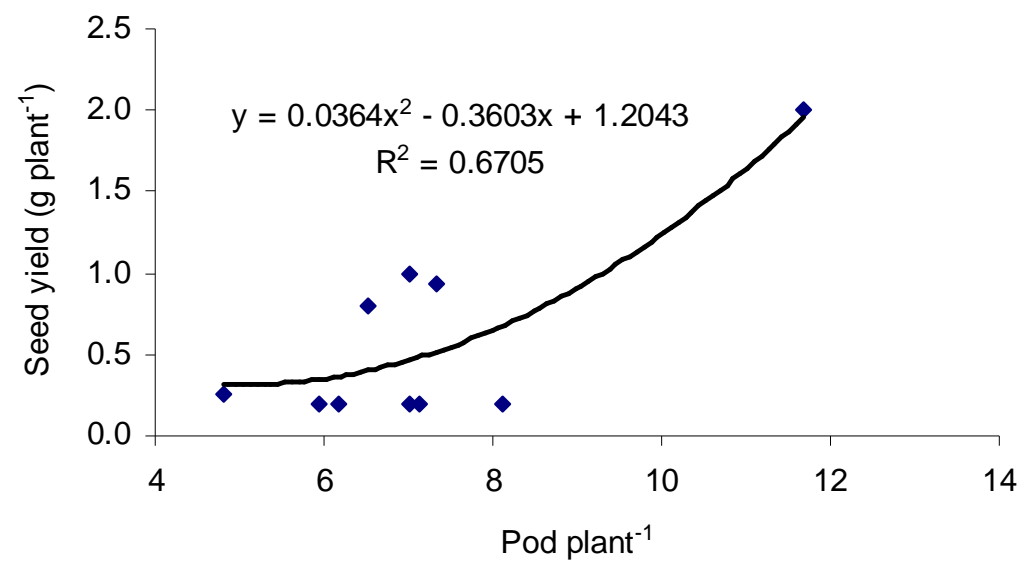

Figure 1. The functional relationship between pod plant ${ }^{-1}$ and seed yield plant $^{-1}$ of 4 days waterlogged plants. 


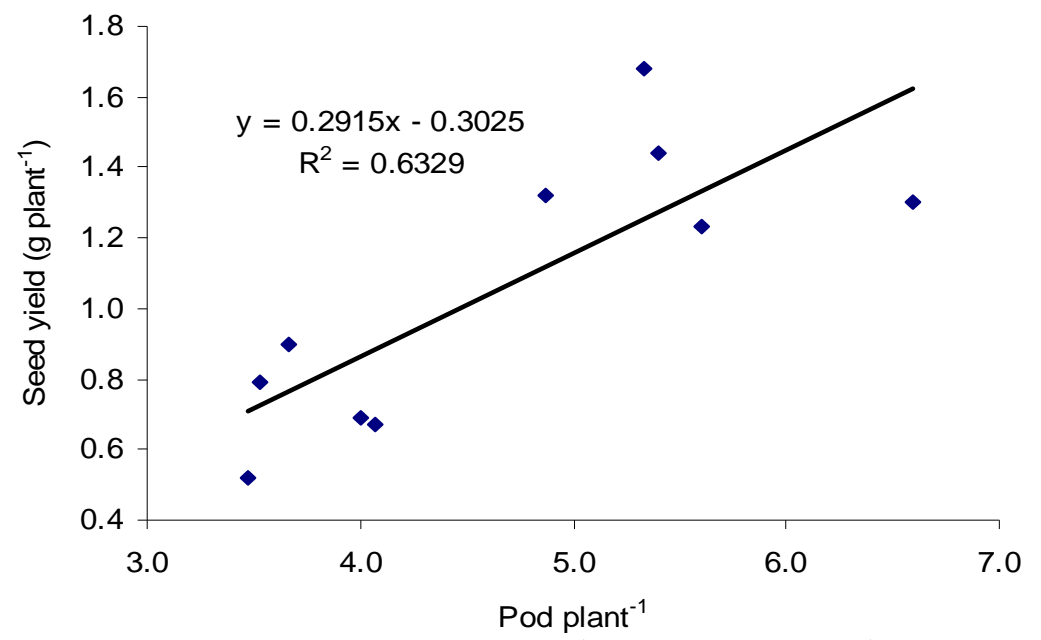

Figure 2. The functional relationship between pods plant ${ }^{-1}$ and seed yield plant ${ }^{-1}$ of 6 days waterlogged plants.

Table 5. Interaction effect of waterlogging period on seed $\operatorname{pod}^{-1}$ of mungbean genotypes.

\begin{tabular}{lcccc}
\hline Genotypes & \multicolumn{5}{c}{ Period of waterlogging } \\
\cline { 2 - 5 } & Control & 2 days & 4 days & 6 days \\
\hline GK-7 & 10.09 & 8.98 & 8.57 & 7.78 \\
GK-48 & 9.63 & 9.33 & 9.44 & 9.14 \\
GK-65 & 9.82 & 9.62 & 9.16 & 7.29 \\
VC-6173A & 10.14 & 9.80 & 8.85 & 8.40 \\
CO-3 & 9.18 & 8.94 & 9.05 & 8.33 \\
IPSA-12 & 9.09 & 9.00 & 8.90 & 7.67 \\
IPSA-13 & 10.08 & 8.51 & 9.31 & 7.31 \\
IPSA-15 & 9.67 & 9.46 & 8.99 & 7.17 \\
BARI Mung-5 & 9.76 & 8.81 & 9.13 & 8.60 \\
BUmung 2 & 9.36 & 8.68 & 9.12 & 7.02 \\
\hline LSD & \multicolumn{5}{c}{0.873} & 6.03 & \\
CV\% & \multicolumn{5}{c}{} \\
\hline
\end{tabular}

The genotype $\mathrm{x}$ treatment interaction on seeds $\operatorname{pod}^{-1}$ was significant under 2,4 and 6 days waterlogging period (Table 5). The number of seed pod $^{-1}$ was unaffected by 2 and 4 days waterlogging period in most genotypes when compared with control treatment. The number of seed pod $^{-1}$ ranged from 8 to 10 both in control and waterlogged plants of all mungbean genotypes and the rate of reduction was negligible. Even 4 days waterlogging period did not affect the number of seed pod ${ }^{-1}$. Islam (2003) did not find any significant difference on the number of seed $\operatorname{pod}^{-1}$ due to waterlogging at different growth stages as a well as across genotypes.

Irrespective of genotypes, the number of seeds pod $^{-1}$ decreased to different rates ranged from 
$5.08 \%$ to $27.48 \%$ over the control when plants were waterlogged for 6 days. Seed pod $^{-1}$ differed significantly in waterlogged plants in all the mungbean genotypes except GK-48 and CO-3 performing the lowest percentage of reduction 5.08 and $9.25 \%$ respectively. Seeds $\operatorname{pod}^{-1}$ decreased to different rates varying from $11.88 \%$ in BARI mung-5, $15.62 \%$ in IPSA-12, $17.15 \%$ VC-6173A, $22.89 \%$ in GK-7, $25.00 \%$ in BUmung 2, 25.76\% in GK-65, 25.86\% in IPSA15 , and $27.48 \%$ in IPSA-13.

\section{Seed weight}

The seed size is a stable varietal character and governs by the genotypes. The genotypic differences in seed size were highly evident. Seed sizes were relatively large in the genotypes IPSA-13 (52), GK-65 (42g), BUmung 2 (42g), BARI Mung-5 (41g), and VC-6173A (41g) under control treatment and decreased depending on the period of waterlogging. The genotype $x$ treatment interaction was significant on seed size when plants were waterlogged for 2, 4 and 6 days (Table 6). One thousand seed weight was reduced to a little extent due to the effect of 2 days waterlogging such as in VC-6173A (3.43\%), BUmung $2(2.90 \%)$ and IPSA-15 $(2.75 \%)$. The highest percentage of reduction over control treatment was in GK-65 (24.14\%) and other genotypes were less affected by 2 days waterlogging period viz. GK-7 (7.16\%), GK-48 (5.06\%), CO-3 (5.53\%), and IPSA-12 (7.08\%). BARI Mung-5 (4.77\%).

The functional relationship $(\mathrm{r}=0.72)$ between 1000 -seed weight and seed yield plant ${ }^{-1}$ of 2 days waterlogged plants showed linear association (Fig. 3).

There was a significant reduction in seed size of 4 days waterlogged plants in all the genotypes. The higher percentage of reduction over control treatment was recorded in IPSA-12 (36.55\%), CO-3 (33.92\%), GK-65 (25.06\%), and BUmung $2(23.53 \%)$. The other genotypes were less affected and the rate of reduction was about $7 \%$ in GK-7, GK-48, IPSA-13, IPSA-15, BARI mung-5 and the lowest was in VC-6173A $(3.91 \%)$. Similar result in reduction in seed size of waterlogged copwpea cultivars was found by Umaharan et al. (1997). The functional relationship ( $\mathrm{r}=0.78$ ) between 1000 -seed weight and seed yield plant $^{-1}$ of 4 days waterlogged plants showed exponential association (Fig. 4). The relationship indicated that 1000 -seed weight of mungbean genotypes when exceeded $35 \mathrm{~g}$ contributed much in the increment in seed yield plant $^{-1}$.

Table 6. Interaction effect of waterlogging period on 1000-seed weight $\left(\mathrm{g}\right.$ plant $\left.{ }^{-1}\right)$ of mungbean genotypes.

\begin{tabular}{|c|c|c|c|c|}
\hline \multirow[t]{2}{*}{ Genotypes } & \multicolumn{4}{|c|}{ Period of waterlogging } \\
\hline & Control & 2 days & 4 days & 6 days \\
\hline GK-7 & 34.18 & 31.73 & 31.75 & 30.93 \\
\hline GK-48 & 31.45 & 29.86 & 29.20 & 21.56 \\
\hline GK-65 & 42.45 & 32.20 & 31.81 & 31.24 \\
\hline VC-6173A & 41.09 & 39.68 & 39.48 & 31.27 \\
\hline $\mathrm{CO}-3$ & 31.63 & 29.88 & 20.90 & 19.82 \\
\hline IPSA-12 & 32.47 & 30.17 & 20.60 & 21.50 \\
\hline IPSA-13 & 52.25 & 50.24 & 48.65 & 41.73 \\
\hline IPSA-15 & 31.64 & 30.77 & 29.33 & 21.24 \\
\hline BARI Mung-5 & 41.74 & 39.75 & 38.57 & 31.30 \\
\hline BUmung 2 & 42.03 & 40.81 & 32.14 & 31.76 \\
\hline $\mathrm{LSD}_{0.05}$ & \multicolumn{4}{|c|}{1.75} \\
\hline $\mathrm{CV} \%$ & \multicolumn{4}{|c|}{3.20} \\
\hline
\end{tabular}




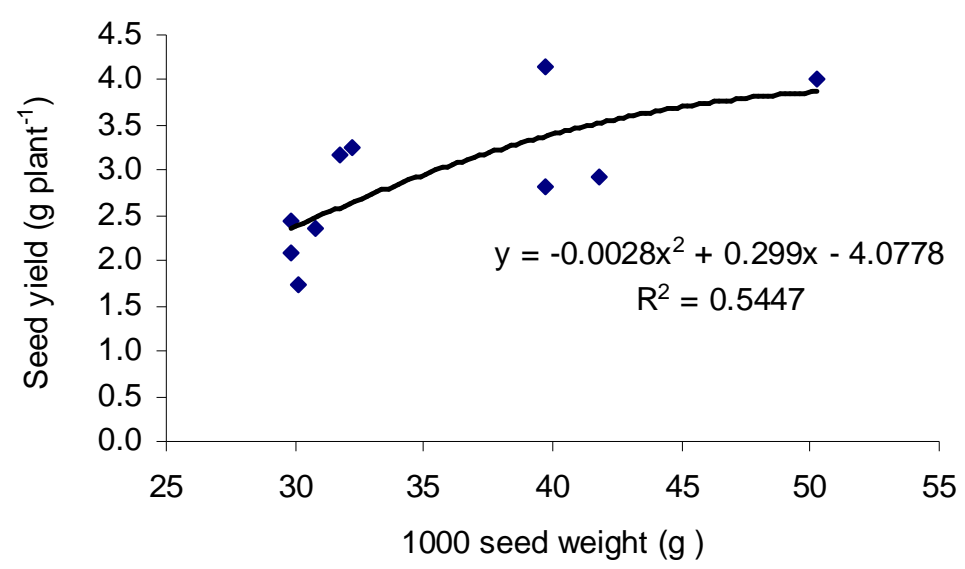

Figure 3. The functional relationship between 1000-seed weight and seed yield of 2 days waterlogged plants

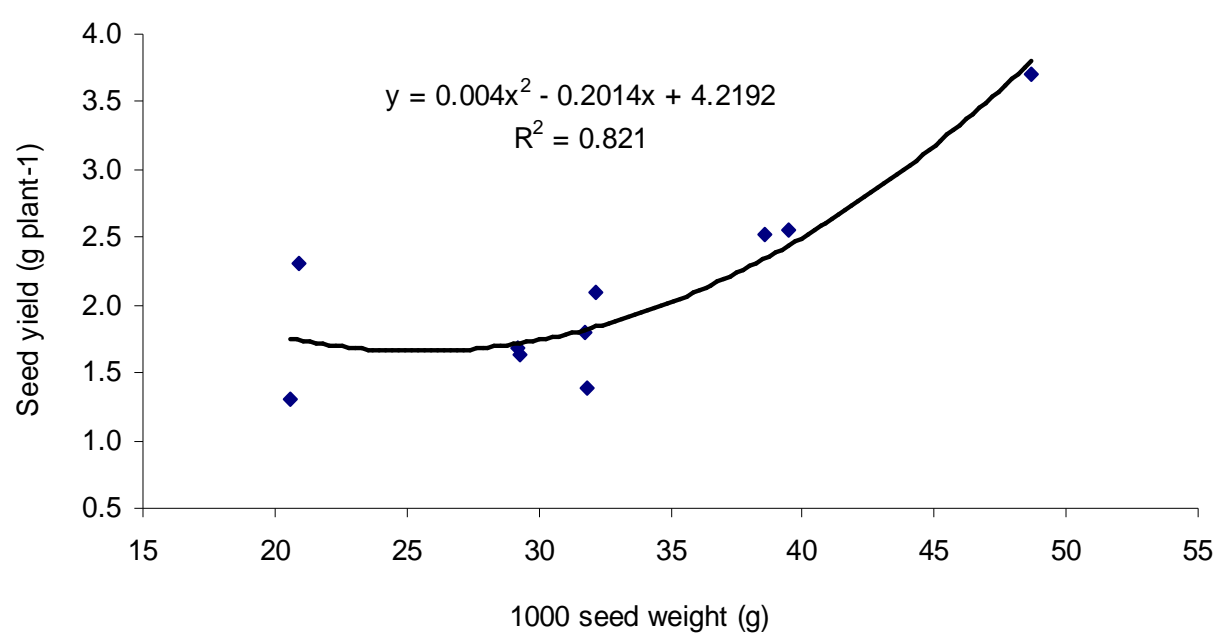

Figure 4. The functional relationship between 1000-seed weight and seed yield of 4 day waterlogged plants

Seed size reduced greatly in 6 days waterlogged genotypes and ranged from $9.50 \%$ to $37.33 \%$ over the non-waterlogged control. From the Table 6, it was obvious that seeds of GK-7 $(9.50 \%)$ were least affected. Seeds of some genotypes were highly affected by longer period of waterlogging viz. GK-48 (31.44\%), GK-65 (26.40\%), VC-6173A (23.90\%), CO-3 (37.33\%), IPSA-12 (33.78\%), IPSA-13 (20.13\%), and IPSA-15 (32.86\%), BARI Mung-5 (25.01\%), and BUmung 2 (24.43\%). Similarly, Nawata et al. (1991) reported that one hundred seed weight of yard long bean was reduced by waterlogging treatments and was smallest in plants subjected to continuous waterlogging. It was probable that poor translocation of assimilates from source to sink resulted in smaller seed size. The functional relationship ( $r=0.72)$ between 1000 -seed weight and seed yield plant ${ }^{-1}$ showed linear relationship (Fig. 5). 


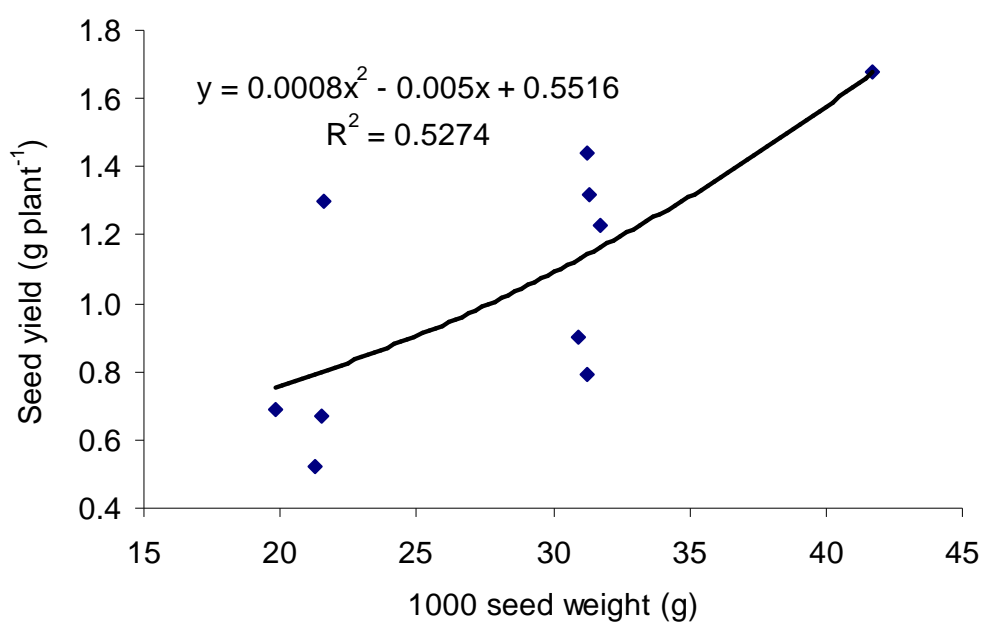

Figure 5. The functional relationship between 1000-seed weight and seed yield of 6 days waterlogged plants.

Table 7. Interaction effect waterlogging period on seed yield $\left(\mathrm{g}\right.$ plant $\left.{ }^{-1}\right)$ and $\%$ yield reduction over control treatment of mungbean genotypes

\begin{tabular}{lcccc}
\hline Genotypes & \multicolumn{4}{c}{ Period of waterlogging } \\
\cline { 2 - 5 } & Control & 2 days & 4 days & 6 days \\
\hline GK-7 & 4.33 & $3.16(27.02)$ & $1.79(58.66)$ & $0.90(79.21)$ \\
GK-48 & 2.61 & $2.08(20.30)$ & $1.68(35.61)$ & $1.30(50.19)$ \\
GK-65 & 4.19 & $3.25(22.43)$ & $1.39(71.69)$ & $0.79(81.14)$ \\
VC-6173A & 4.31 & $4.14(3.94)$ & $2.56(40.60)$ & $1.44(66.58)$ \\
CO-3 & 2.88 & $2.45(14.93)$ & $2.30(10.50)$ & $0.69(73.15)$ \\
IPSA-12 & 2.71 & $1.74(35.79)$ & $1.30(52.02)$ & $0.67(75.27)$ \\
IPSA-13 & 6.92 & $4.02(41.90)$ & $3.71(46.38)$ & $1.68(75.72)$ \\
IPSA-15 & 3.15 & $2.37(24.76)$ & $1.63(48.25)$ & $0.52(83.49)$ \\
BARI Mung-5 & 3.37 & $2.82(16.32)$ & $2.52(25.22)$ & $1.32(60.83)$ \\
BUmung 2 & 3.82 & $2.92(23.56)$ & $2.10(45.02)$ & $1.23(67.80)$ \\
\hline LSD 0.05 & \multicolumn{3}{c}{0.763} \\
CV\% & \multicolumn{3}{c}{19.10} \\
\hline
\end{tabular}

Figures in parenthesis indicate \% yield reduction over control treatment

The mungbean genotypes and waterlogging period interacted significantly on the seed yield (Table 7). The highest seed yield in control treatment was produced by IPSA-13 (6.92g plant $^{-1}$ ) followed by GK-7 (4.33g plant $\left.{ }^{-1}\right)$, VC6173A (4.31 $\mathrm{g} \mathrm{plant}^{-1}$ ) and GK-65 (4.19g plant ${ }^{-1}$ ). Lower yields were recorded in GK-48 (2.61g plant $\left.^{-1}\right)$, CO-3 (2.88g plant $\left.{ }^{-1}\right)$, IPSA-12 (2.71g plant $\left.^{-1}\right)$, IPSA-15 (3.15g plant $\left.{ }^{-1}\right)$ and BARI Mung-5 (3.37g plant $\left.^{-1}\right)$.

Irrespective of mungbean genotypes, the yield reduction ranged from $3.94 \%$ to $41.90 \%$ when plants were waterlogged for 2 days. The highest percentage of reduction was recorded in IPSA-13 $(41.90 \%)$ followed by IPSA-12 (35.79\%), GK-7 
$(27.02 \%)$, and IPSA-15 (24.76\%). Yield reduction in BUmung $2(23.56 \%)$, GK-65 (22.43\%), GK-48 (20.30\%), BARI Mung-5 (16.32\%), CO-3 (14.93\%) and the lowest was in VC-6173A (3.94\%). A closer look revealed that although the rate of reduction over control treatment in IPSA-13 was the highest $(41.90 \%)$ but the seed yield under waterlogged condition was significantly higher than those of other waterlogging exposed genotypes. The larger seed size might contributed to produce higher seed yield in IPSA-13.

Seed yield of control treatment and 4 days waterlogged plants differed significantly among the genotypes except CO-3. Irrespective of genotypes, the percentage of yield reduction over the non-waterlogged control ranged from $10.50 \%$ to $71.69 \%$. The lowest percentage of yield reduction over control treatment was recorded in CO-3 (10.50\%), followed by BARI Mung-5 (25.22\%) and GK-48 (35.61\%). Seed yield reduction of more than $40 \%$ was recorded in VC-6173A (40.60\%), IPSA-13 (46.38\%), BUmung $2(45.02 \%)$ and IPSA-15 (48.25\%). The greater reduction was calculated in IPSA-12 (52.02\%), GK-7 (58.66\%), and GK-65 (71.69\%). Minchin et al. (1978) reported $48 \%$ loss in yield of cowpea in response to waterlogging during the vegetative phase under simulated tropical conditions.

Waterlogging for 6 days significantly affected seed yield of mungbean genotypes and the rate of reduction in seed yield ranged from $50.19 \%$ to $83.49 \%$ irrespective of genotypes. This indicates how badly the plants were affected by 6 days waterlogging. The cause of reduction in seed yield might be due to the bearing of very few pods plant ${ }^{-1}$ and reduction in seed size. Nawata et al. (1991) observed significant reduction in seed yield of yard long bean (about $75 \%$ of the control) by long-term (16 days) waterlogging treatment. The lowest yield reduction over control treatment was observed in GK-48 (50.19) followed by BARI Mung-5 (60.83\%) and VC6173A (66.58\%) and BUmung $2(67.80 \%)$. The greater reduction was recorded in $\mathrm{CO}-3$
$(73.15 \%), \quad$ IPSA-12 (75.27\%), IPSA-13 (75.72\%), GK-7 (79.21\%) and IPSA-15 (83.49\%). Islam (2003) reported that longer period of waterlogging significantly reduced the seed yield of mungbean. Wang et al. (2013) reported that yield loss due to waterlogging may vary between $15 \%$ and $80 \%$ depended on the crop species and growth stage, soil type and duration of the stress.

\section{Conclusions}

Waterlogging period affected the growth and yield of mungbean genotypes. Yield and yield contributing characters of mungbean genotypes differed significantly due to duration of waterlogging which was depended on their tolerance ability. The genotypes tolerant to waterlogging during vegetative phase recovered rapidly its growth and maintained the reproductive period avoiding waterlogging stress. The genotypes that showed greater reduction in seed yield had seemingly lost their ability to adapt waterlogging conditions. The study further revealed that mungbean genotypes IPSA-13, VC-6173A, BUmug 2, BARI Mung-5 and IPSA-12 could adapt to longer period of waterlogging than the others.

\section{Acknowledgement}

We are most grateful to the Director, Project Implementation Unit (PIU) as this research was supported by operating grants from "National Agricultural Technical Project (NATP: PhaseI)", Bangladesh Agricultural Research Council, Farmgate, Dhaka-1215, Bangladesh.

\section{References}

Ahmed, S., Nawata E. and Sakuratani, T. 2002. Effects of waterlogging at vegetative and reproductive growth stages on plant photosynthesis, leaf water potential and yield in mungbean. Plant Production Science, 5:117-123.

Bagga, A.K., Bela, M. and Tomar, O.P.S. 1984. Effect of short duration of waterlogging on water use efficiency of two mungbean 
(Vigna radiata (L.) Wilczek) varieties. Indian Journal of Physiology, 27:159-165.

Cannell, R. Q., Gales, K., Saydon, R.W. and Suhail, B.A. 1979. Effect of short-term waterlogging on the growth and yield of pea (Pisum sativum). Annals of Applied Biology, 93:327-335.

Crawford, R.R. M. and Brandle, R. 1996. Oxygen deprivation stress in a changing environment. Journal of Experimental Botany, 47:145-159.

Gomez, K.A. and Gomez, A.A. 1984. Statistical Procedures of Agricultural Research. $2^{\text {nd }}$ edn., John Wiley and Sons. Singapore, $680 \mathrm{p}$.

Greenway, H., Gibbs, J. and Setter, T. 1994. Mechanisms of tolerance to waterlogging and submergence. IRRI. The Philippines. UWA and IRRI, Pub.136:8.

Hamid, A., Agata, W., Moniruzzaman, A.F.M. and Miah, A.A. 1991. Physiological aspects of yield improvement in mungbean. Proc. of the Second National Workshop on Pulses, 6-8 Jan, 1989, BARI, Gazipur (Bangladesh), 87-94 pp.

Islam, M.R. 2003. Eco-physiology of soilflooding tolerance in mungbean. A Ph.D. thesis. Bangabandhu Sheikh Mujibur Rahman Agricultural University, Salna, Gazipur-1706, Bangladesh.

Islam M.R., Akter N., Parvez, S.M.S. and Haque, K.M.S. 2014. Growth and yield response of mungbean (Vigna radiata $\mathrm{L}$. Wilczek) genotypes to wet puddling, flooding and saturated soil culture. Journal of Plant Sciences, 2(6):311-316.

Islam, M.R., Hamid, A., Karim, M.A., Haque, M.M., Khaliq, Q.A. and Ahmed, J.U. 2008. Gas exchange and yield responses of mungbean (Vigna radiata L. Wilczek) genotypes differing in flood tolerance. Acta Physiologiae Plantarum, 30:697707.
Islam, M.R., Hamid, A., Khaliq, Q.A., Ahmed, J.U., Haque, M.M. and Karim, M.A. 2007. Genetic variability in flooding tolerance of mungbean (Vigna radiata $\mathrm{L}$. Wilczek) genotypes. Euphytica, 156:247255.

Islam, M.T. 1994. Eco-physiological studies on photosynthesis and dry matter production in mungbean (Vigna radiata (L.) Wilczek). Ph.D. thesis. Kyushu Univ. Fukuoka, Japan.

Jackson, M.B.1979. Rapid injury to peas by soil waterlogging. Journal of the Science of Food and Agriculture, 30: 143-152.

Jackson, M.B.1983. The impact of flooding stress on plant and crops. School of Biol. Sci. Univ. of Bristol, Bristol. UK. Plant Ecophysiology, Faculty of Biol. Univ. of Utrecht. Sorbonnelaan. Utrecht, The Netherlands. 1-29 pp.

Kozlowski, T.T. 1984. Plant responses to flooding. Bioscience 34: 162-167. In: Rubio et al. (ed.) Oecologia (1995), 102:102-105.

Kumar P., Pal, M., Joshi, R. and Sairam, R.K. 2013. Yield, growth and physiological responses of mungbean [Vigna radiata (L.) Wilczek] genotypes to waterlogging at vegetative stage. Physiology and Molecular Biology of Plants, 19 (2):209220.

Leul, M. and Zhou, W. J. 1999. Alleviation of waterlogging damage in winter rape by uniconazole application: Effects on enzyme activity, lipid peroxidation, and membrane integrity. Journal of Plant Growth Regulation, 18:9-14.

Miah, A.A., Moniruzzaman, A.F.M. and Rahman, M.M. 1991. Problems and prospects of pulses production. Proc. of the Second National Workshop on Pulses, 6-8 Jan, 1989, BARI, Gazipur (Bangladesh), 87-94 pp. 
Minchin, F.R., Summerfield, R.J., Eaglesham, A.R.J. and Stewart, K.A. 1978. Effects of short-term waterlogging on growth and yield of cowpeas (Vigna unguiculata). Journal of Agricultural Science, Cambridge University Press. 90:355-366.

Nawata, E. 1989. Analysis of the responses of yard long bean to waterlogging. A Ph.D. thesis. Kyoto University, Japan.

Nawata, E., Yoshinaga, S. and Shigenaga, S. 1991. Effects of waterlogging duration on the growth and yield of yard long bean (Vigna sinensis var. sesquipedalis). Elsevier Science Publishers B.V. Scientia Horticulturae, 48:185-191.

Rosario, D.A. and Faustino, F.C. 1986. Screening for drought resistance in mungbean.pp. 188-206. Proc. of the Workshop on Varietal Improvement of Rice Based Farming Systems. 11-15 Mar. 1985. Thailand.

Umaharan, P., Ariyanayagam, R.P. and Haque, S.Q. 1997. Effect of short-term waterlogging applied at various growth phases on growth, development and yield in Vigna unguiculata. Journal of Agricultural Science, Cambridge University Press. 128:189-198.

Vartapetian, B.B. and Jackson, M.B.1997. Plant adaptations to anaerobic stress. Annals of Botany, 79 (Supplement A): 320.

Wang, M., Zheng, Q., Shen, Q. and Guo, S. 2013. The critical role of potassium in plant stress response. Nanjing Agricultural University, Weigang, Nanjing 210095, China. International Journal of Molecular Sciences, 14:7370-7390.

Wien, C., Lal, R. and Pulver, E.L. 1979. Effects of transient flooding on growth and yield of some tropical crops. In 'Soil Physical Properties and Crop Production in the Tropics' (Eds. R. Lal and D.J. Greenland. John Wiley \& Sons, Chichester. 234-245 pp.

Yadav, R.S. and Saxena, H.K. 1998. Response of waterlogging on growth and seed yield of mungbean (Vigna radiata (L.) Wilczek). Indian Journal of Plant Physiology, 3:7172. 